missile, about twenty centimetres in diameter and thirty centimetres long, is guided either by active radar or by far-infra-red seekers. Infra-red has special advantages because satellites give distinct thermal 'fingerprints'. More than ten homing missiles are carried into orbit by a highly manoeuvrable platform whose orbit is directed so as to provide the opportunity to fire missiles at the maximum number of target satellites within a minimum number of orbits. Free-fall tests of the infra-red guidance system have demonstrated mid-air activation, target acquisition and guidance to impact with a target. Electronic countermeasures against infra-red seekers (which are passive detectors, emitting no signal of their own) are more difficult than for active radar; and it is difficult for satellites to make rapid evasive manoeuvres in orbit. A similar system involving missiles armed with conventional warheads has also been under investigation.

\section{Interpreting Soviet tests}

By comparison, Soviet tests have only obliquely suggested a preference for destruction by large explosions in the vicinity of the target satellite. Since Soviet tests have never resulted in the physical destruction of a target, the explosion of the interceptor could be explained as a test of the vulnerability of the target to attack-rather than demonstrating the potential of the interceptor to destroy target satellites. The difficulty in interpreting properly the explosions in the Cosmos series also lends support to the idea that Soviet killer satellites may soon carry laser or ion-beam weapons. In any case the Soviet and American hunterkiller satellite developments should not he directly compared because each Super Power has very different approaches to the development of major weapon systems.

Presently US space defence research is concentrated upon problems of hardening satellites against attack and increasing the resistance of communication, command, and control transmissions to jamming. These battlefield transmissions now rely almost completely on satellites. The third generation of American military communications satellites now being developed employ a technique of using multiple directional beams for transmission, and of shifting frequencies in the ultra and super high frequency bands ( 7 to $8 \mathrm{GHz}$ ) to avoid the effects of jamming. Satellite antennae are being developed that use electronic counter-measures to eliminate the effect of a directional jamming beam fixed on the satellite. Solar cells are being designed and built to withstand the effects of intense heating and radiation, by using filter coatings which do not absorb energy at typical laser wavelengths, and by using construction techniques with materials with high resistance to heat and radiation damage. The vulnerability of solar cells has led to an increased interest in nuclear power sources for satellites which until now have always

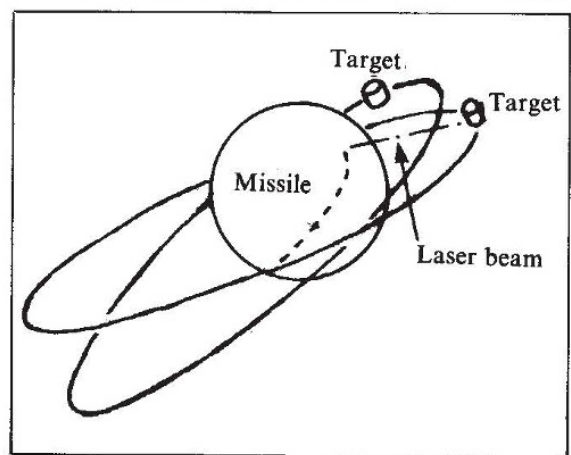

The Soviet system can only knock out one satellite at a time making it ineffective against the US global positioning array of 36 satellites

had the disadvantage of being much heavier and considerably more costly to operate. Three designs are currently under consideration all of which use $\mathrm{P}^{236}$ isotopes as the power source. With the considerable improvements in performance that are being achieved for satellites military dependence on them can be expected to increase throughout the 1970s and early 1980s. During the first half of the 1970s military missions accounted for about half of the American satellite launches and both the number of military satellites and their relative size and payload will increase further as the NASA Space Shuttle

\section{begins operation.}

The development of killer satellites is unlikely to provide any significant strategic advantage for either Super Power and the race to develop them is likely to be very costly. A surprise attack is hard to achieve with killer satellites because the preliminary manoeuvres are easily detected by other satellites. It is also possible to place in distant orbits satellites which are ready to replace ones destroyed by an attack. These so-called 'dark' satellites have characteristics such as very small radar cross-sections and low reflectivity which make them very difficult to detect and track. Because of their distant orbits they are relatively safe from attack in the first instance. The real advantage of destroying military satellites in a strategic nuclear conflict would appear only if one side destroyed a significant number of the opponent's satellites while retaining its own. A rapid destruction of all satellites would yield no advantage to either side.

It is perhaps to avoid a costly arms race that both the Soviet Union and the United States are anxious to reach an agreement limiting the development of killer satellites. The United States was reported to have requested Soviet consideration of such an agreement last March. The Soviet response was favourable and the United States National Security Council are presently considering a formal policy based on reports by various departmental agencies on the implications and verification problems of a hunter-killer satellite limitation or ban. The intention is to provide for an agreement separate to SALT and talks on a possible agreement over limiting killer satellite development may begin this Soring. Meanwhile US Defense Department officials are concerned that present programmes should not be effected by the agreement and it is unlikely that the incentive given to US space defence research by the recent Soviet testing of the Cosmos satellites will be abated by a limitation-unless the form of the agreement is radically different to those which have been made in other areas of strategic arms control.

\title{
1979 looks like a good year for US science
}

Climatology, reproductive and developmental biology, and military-related basic research are three areas of science likely to receive a major boost from President Carter's Budget for the fiscal year 1979, which was submitted to Congress on Monday.

Other areas to benefit from a budget that proposes an overall increase of $10.9 \%$-about $5 \%$ above expected in- flation levels-for basic science include solar studies, which is given the green light for two major projects, and earthquake research. Potential casualties include one of the five planned space shuttles, and the Clinch River liquid metal fast breeder neactor demonstration project. The proposed termination of the Clinch River project would save about $\$ 150$ million, and would result in virtually no increase in the energy nesearch and development budget overall.

In general, the budget carries an optimistic message for basic science, in line with the results of a broad-ranging survey of the nation's resarch activities carried out at the President's request by the Office of Science and Technology Policy (OSTP). The projected 
increase in spending on basic research is precisely the level recommended by the President's Science Adviser, Dr Frank Press, who claims " $100 \%$ support" from the Office of Management and Budget.

But if previous budgets could be described as Keynesian, this one returns to a more classical, monetarist mould. Emphasis in funding is shifted away from development projects (for example in solar heating technology) which are felt to be the responsibility of the private sector and its market forces, back to more basic "long term" considerations.

Thus within an overall increase in support for research and development of $6.1 \%$, to a total of $\$ 27,900$ million, the main increase will take place in basic science, from $\$ 3,288$ million in 1978 to $\$ 3,647$ million in 1979 . In contrast the budget for applied research will increase by only $7.4 \%$ from $\$ 6,248$ million to $\$ 6,711$ million, and for development by an even lower rate of $4.6 \%$, from $\$ 16,753$ to $\$ 17,532$ million.

A major beneficiary of the increased funding for basic research will be universities and colleges, many of whose problems - such as the obsolescence of equipmenit and the lack of opportunities for young scientists-were brought to the President's attention by the OSTP survey. Total R \& D support for colleges is therefore suggested to rise from \$3,300 million in 1978 to $\$ 3,561$ million in 1979 , an overall increase of $7.9 \%$, with particularly large increases in funds for agricultural $(10.7 \%)$, energy $(11.7 \%)$, and military research. (In the light of the benefits which these increases are expected to bring, the NSF's pnoposed basic research stability grants, whose $\$ 4.5$ million was "impounded" by the President from the 1978 budget a few months ago, will be permanently dropped.)

One area to receive a major boost is olimate research. A broad initiative in this area, involving eight agencies and a $39 \%$ increase in funding to $\$ 104 \mathrm{mil}-$ lion, will be coordinated by the National Oceanic and Atmospheric Administration of the Department of Commerce.

Three important aspects of the proposed 1979 budget will be: the development of satellite sensors for ozone and earth radiation monitoring - a major field study of the equatorial Pacificand basic research on carbon dioxide levels in the atmosphere and oceans.

Two new programmes are included in the budget of the National Aeronautics and Space Administration (NASA). The first of these is the Solar Polar Mission, a joint project with the European Space Agency to send two space craft, launched from the Space Shuttle in 1983, past Jupiter, in an orbit that will permit the first study of the polar regions of the sun. And the second project is the Solar Mesospheric Explorer, which will permit study of the effects of solar radiation on the earth's ozone layer.

At the Department of Health, Education and Welfare, whose basic research budget is proposed to be increased by $14.9 \%$ to $\$ 992$ million, areas scheduled for increased suppont include reproduction and family planning, developmental biology, and child development, as well as the potential environmental hazards to human health.

There are bright prospects, too, for military-related basic nesearch. Spending by the Department of Defense is proposed to increase by $14 \%$, almost as much as for health research, reflecting the view of Defense Secretary Dr Harold Brown that this area has been underfunded in necent years.

One result of this will, according to Dr Press, be the re-establishment of connections between the military establishment and the university research community which, he says, "have been allowed to dapse in recent years" and the R \& D budget of the Department of Energy includes provision for work on the controversial neutron bomb.

The future for basic research-at least in most areas - therefore looks better than it has for several years past. But the leit-motif remains that of the ultimate pay-off. Dr Press, pointing out that the applications of basic science may take 10 or 20 years to come through, characterises this as an anea in which industry tends as a consequence to "underinvest", thus justifying increased federal expenditure. And Dr Robert Frosch, administrator of NASA, ended his statement on the Agency's budget with the words that it would "give the American taxpayer the return on his investment he expects and deserves".

This approach is also reflected in the budget of the NSF. One anea due for slignificant expansion, for example, is the integrated basic nesearch programme of the new Applied Science and Research Application Dinectorate.

\begin{tabular}{lccc}
\hline Federal funding for conduct of R and D by Agency (in millions of dollars) \\
\hline Department or Agency & \multicolumn{2}{c}{ Obligations } & \% increase 1979 \\
& 1978 & 1979 & $\mathbf{1 9 7 8}$ \\
over & 19,709 & 12,740 & 8.8 \\
Defense-military functions & 4,231 & 4,245 & 9.3 \\
Energy & 3,877 & 4,193 & 8.2 \\
HASA & 3,137 & 3,258 & 3.9 \\
NSF & 754 & 829 & 10.0 \\
Agriculture & 626 & 632 & 1.0 \\
Environmental Protection & 351 & 358 & 2.0 \\
Transportation & 364 & 342 & -6.0 \\
Interior & 366 & 340 & -7.1 \\
Commerce & 288 & 316 & 9.7 \\
All other* & 587 & 637 & 8.5
\end{tabular}

*Includes the Department of Justice, Labour and State, The Veterans Administration, The Civil Service Com mission, the Corps of Engineers, the Federal Trade Commission, the Tennessee Valley Authority, and the Library of Congress.

TOTAL

26.287

$\mathbf{2 7 , 8 0 0}$

6.1
This is scheduled for an increase from $\$ 1.9$ to $\$ 7.0$ million, and will be concerned with "identifying basic nesearch relevant to significant national problems", jointly with the basic research directorate of NSF.

One area to have suffered from this cost-conscious approach is high energy physics, whose budget is planned to expand by only $6.7 \%$. The budget allows substantial sums for the construction of the intersecting storage accelerator (Isabelle) at Brookhaven, and for a new high-intensity beam facility at the Lawrence Berkeley Laboratory.

At Fermilab in Illinois, however, although the energy saver/doubler project is being formally moved from the $\mathrm{R} \& \mathrm{D}$ to the construction phase, only $\$ 10$ million of the proposed authorisation of $\$ 38.9$ million for construction is scheduled to be spent in 1979-and this will be partially met by reducing the $\$ 86.1$ million authorised for running costs in 1978 and $\$ 81.8$ mitilion authorised in 1979 .

But if the cost/benefit consciousness that runs through the proposed budget has resulted in decisions that are unwelcome in some quarters, it is likely to increase the chances of the budget proposals being looked upon favourably by Congress.

Last year, the substantial increases for research and development requested by President Ford in his outgoing budget were received sceptically. Although making a considerable, and almost traditional, increase in the NIH budget, Congress reduced the request for the NSF, for example, from $\$ 885$ million-a figure which NSF Director Dr Richard Atkinson admits "we were not able to defend"一to $\$ 863$ million.

This year the OSTP has done the President's homework. And there will be both substantial evidence, and the carefully-considered support of departmental and agency heads, to back up demands in the face of Congressional cross-examination. So the signs are that 1979 will be a good year for scientists.

David Dickson 